\title{
Review
}

\section{Release and activity of histone in diseases}

\author{
R Chen ${ }^{1,2}$, R Kang ${ }^{2}$, X-G Fan ${ }^{*, 1}$ and D Tang ${ }^{\star, 2}$
}

Histones and their post-translational modifications have key roles in chromatin remodeling and gene transcription. Besides intranuclear functions, histones act as damage-associated molecular pattern molecules when they are released into the extracellular space. Administration of exogenous histones to animals leads to systemic inflammatory and toxic responses through activating Toll-like receptors and inflammasome pathways. Anti-histone treatment (e.g., neutralizing antibodies, activated protein C, recombinant thrombomodulin, and heparin) protect mice against lethal endotoxemia, sepsis, ischemia/ reperfusion injury, trauma, pancreatitis, peritonitis, stroke, coagulation, and thrombosis. In addition, elevated serum histone and nucleosome levels have been implicated in multiple pathophysiological processes and progression of diseases including autoimmune diseases, inflammatory diseases, and cancer. Therefore, extracellular histones could serve as biomarkers and novel therapeutic targets in human diseases.

Cell Death and Disease (2014) 5, e1370; doi:10.1038/cddis.2014.337; published online 14 August 2014

\section{Facts}

- Histones and their post-translational modifications have key roles in chromatin remodeling and gene transcription.

- In addition to nuclear function, histones function as DAMPs when they translocate from the nucleus to the extranuclear space.

- Extracellular histones bind to receptors and trigger activation of multiple signaling pathways in a single or combined manner.

- High concentrations of serum histones are detected in several human diseases.

\section{Open Questions}

- What are the distinct roles of individual histones in cell death, inflammation, and immunity?

- What controls the secretion and release of histones?

- What is the structural basis of the regulatory activity of extracellular histones?

- How do histones qualitatively and quantitatively sense different forms of stressors in different cells?

Histones, first discovered by Albrecht Kossel in 1884, are highly conserved, alkaline, positively charged proteins. ${ }^{1}$ Histones have long been considered unique to eukaryotic cells throughout history, yet studies have demonstrated that histone homologs exist in select archaea. They are basic unit structure components of chromatin, namely nucleosomes (Figure 1). It is clear that lack of histones leads to disorganized and ineffectively structured human genomic DNA. ${ }^{1}$ Moreover, histone post-translational modifications (PTMs) have a critical role in the regulation of nucleosome dynamics and multiple DNA-associated processes such as transcription, replication, and repair. ${ }^{2,3}$ Various histone PTMs and their combinations lead to the generation of the histone code hypothesis and epigenetic theory, which were first proposed by Brian D Strahl and C David Allisin in 2000. ${ }^{4}$ Emerging studies indicate that besides having nuclear function, histones can also be released into the extracellular space by both damaged and activated cells, exhibiting significant toxic or pro-inflammatory activity in vivo and in vitro. ${ }^{5,6}$ These special properties make histones a new member of the damage-associated molecular pattern molecules (DAMPs). ${ }^{7-9}$ Studies in both animal models and patients have suggested that dynamic changes in circulating levels of histones as well as nucleosomes serve as potential biomarkers and novel therapeutic targets in several diseases. In this review, we will summarize the basics of histones and focus on the biological functions and clinical relevance of extracellular histones in diseases.

\section{Histone Structure and Nucleosome Assembly}

Over the past few decades, structural biology techniques have identified the high-resolution structures of histones. There are five members of histones, categorized into two

\footnotetext{
${ }^{1}$ Department of Infectious Diseases and State Key Lab of Viral Hepatitis, Xiangya Hospital, Central South University, Changsha, Hunan, China and ${ }^{2}$ Department of Surgery, University of Pittsburgh, Pittsburgh, PA, USA

${ }^{*}$ Corresponding author: X-G Fan, Department of Infectious Diseases, Xiangya Hospital, Central South University, Changsha, Hunan, China. Tel: +86 73184328926 ; Fax: +86 731 84327332; E-mail: xgfan@ hotmail.com

or D Tang, Department of Surgery, University of Pittsburgh, G.27C Hillman Cancer Center, 5117 Center Avenue, Pittsburgh, PA 15232, USA. Tel: +1 412 6231211; Fax: +1 412 6231212; E-mail: tangd2@upmc.edu

Abbreviations: APC, activated protein C; ALI, acute lung injury; COPD, chronic obstructive pulmonary disease; DAMP, damage-associated molecular pattern molecule; hcDNA, histone-complexed DNA fragment; HMGB1, high mobility group box 1; MAPK, mitogen activated protein kinase; NET, neutrophil extracellular trap; PTM, post-translational modification; PSA, polysialic acid; rTM, recombinant thrombomodulin; TNF- $\alpha$ tumor necrosis factor- $\alpha$; TLR, Toll like receptor

Received 06.6.14; revised 03.7.14; accepted 07.7.14; Edited by A Stephanou
} 
groups: core histones ( $\mathrm{H} 2 \mathrm{~A}, \mathrm{H} 2 \mathrm{~B}, \mathrm{H} 3$, and $\mathrm{H} 4)$ and linker histones ( $\mathrm{H} 1$ and $\mathrm{H} 5)$. The four core histones have similar structures with a conserved central motif domain (termed as histone fold) and an unstructured amino-terminal tail. Histone fold is composed of a long central $\alpha$-helix with a loop or a short helix flanked on either side. In addition, the $\mathrm{N}$-terminal of core histones has a basic region that extends through the DNA gyres and into the space surrounding the nucleosomes, which provides sites for multiple PTMs. The four core histones form an octane, the basic core particle of nucleosomes (Figure 1), and exist as an intact entity at high ionic strengths. Meanwhile, the linker histone $\mathrm{H} 1$ associates with nucleosome and facilitates the construction of numerous nucleosomes into higher-order chromatin structures. Moreover, $\mathrm{H} 5$, a variant of $\mathrm{H} 1$, is the predominant linker histone in avian erythrocytes. Many lysines in $\mathrm{H} 1$ are replaced by arginines in $\mathrm{H} 5$.

The most important function of histone in the nucleus is to construct nucleosomes, which are the basic subunits of chromatin. The nucleosome consists of $\sim 147 \mathrm{bp}$ of DNA wrapped in about one and half turns around an octameric protein core containing two $\mathrm{H} 2 \mathrm{~A}-\mathrm{H} 2 \mathrm{~B}$ dimers and one $(\mathrm{H} 3-\mathrm{H} 4)$ tetramer (Figure 1). ${ }^{10}$ Every two of the core histones bind together to form dimers, which are further assembled in a characteristic protein structure, termed as the 'handshake' motif. The dimer stabilization mainly depends on hydrophobic interactions that spread over the entire region of the histone fold in each monomer. Moreover, two $(\mathrm{H} 3-\mathrm{H} 4)$ heterodimers further associate to form a tetramer, which has an important role in nucleosome assembly initiation. In contrast, the (H2A$\mathrm{H} 2 \mathrm{~B}$ ) homodimer is not inclined to further association into a tetramer. Thermodynamic study on $\mathrm{H} 2 \mathrm{~A}-\mathrm{H} 2 \mathrm{~B}$ shows that the histones are stable, structured entities only when they are complexed as part of a dimer. Finally, $\mathrm{H} 1$ associates with the core particle to form the nucleosome containing $\sim 200 \mathrm{bp}$ of DNA.

\section{Histone Modification and Epigenetic Code}

Precise regulation of gene expression is critical for various developmental, physiological, and pathological processes. Changes in chromatin's structure and function affect gene transcription and expression through fine-tuned mechanisms. Chromatin presents in two forms: euchromatin with higher transcriptional activity and heterochromatin with lower transcriptional activity. ${ }^{11}$ Euchromatin is a loosely packed form that usually localizes transcriptional initiation regions such as promoter and enhancer elements of the gene. In contrast, heterochromatin is a tightly packed form usually close to the transcriptionally inactive region. These two different structural forms of chromatin can be switched through epigenetic modifications, which result in gene repression or activation. ${ }^{11}$ Covalent PTMs of the N-terminal tail of core histones are one of the prominent means to regulate chromatin status, structure, and gene expression. ${ }^{3}$ These PTMs, including acetylation, methylation, phosphorylation, ubiquitination, citrullination, sumoylation, biotinylation, or ADP ribosylation, often act in combination with one another (Figure 2). ${ }^{12,13}$ Histones can be modified multiple times by different PTMs or by the same PTM at different residues. For example, Iysine residues can be either methylated or acetylated in a separate or sequential manner. In particular, lysine can be mono-, di-, or tri-methylated. ${ }^{14}$ All possible combination patterns of PTMs on histones establish a so-called 'histone code' in a transient or quite stable manner. ${ }^{4}$ Moreover, the epigenetic codes, including histone code and other epigenic modifications such as DNA methylation, regulate chromatin organization and DNA utilization processes (Figure 2).

Of all the histone modifications, methylation and acetylation of cores $\mathrm{H} 3$ and $\mathrm{H} 4$ are well- studied and have central epigenetic roles in the regulation of gene transcription. In general, acetylation of lysine by histone acetyltransferases in the promoter regions of histones results in a switch from

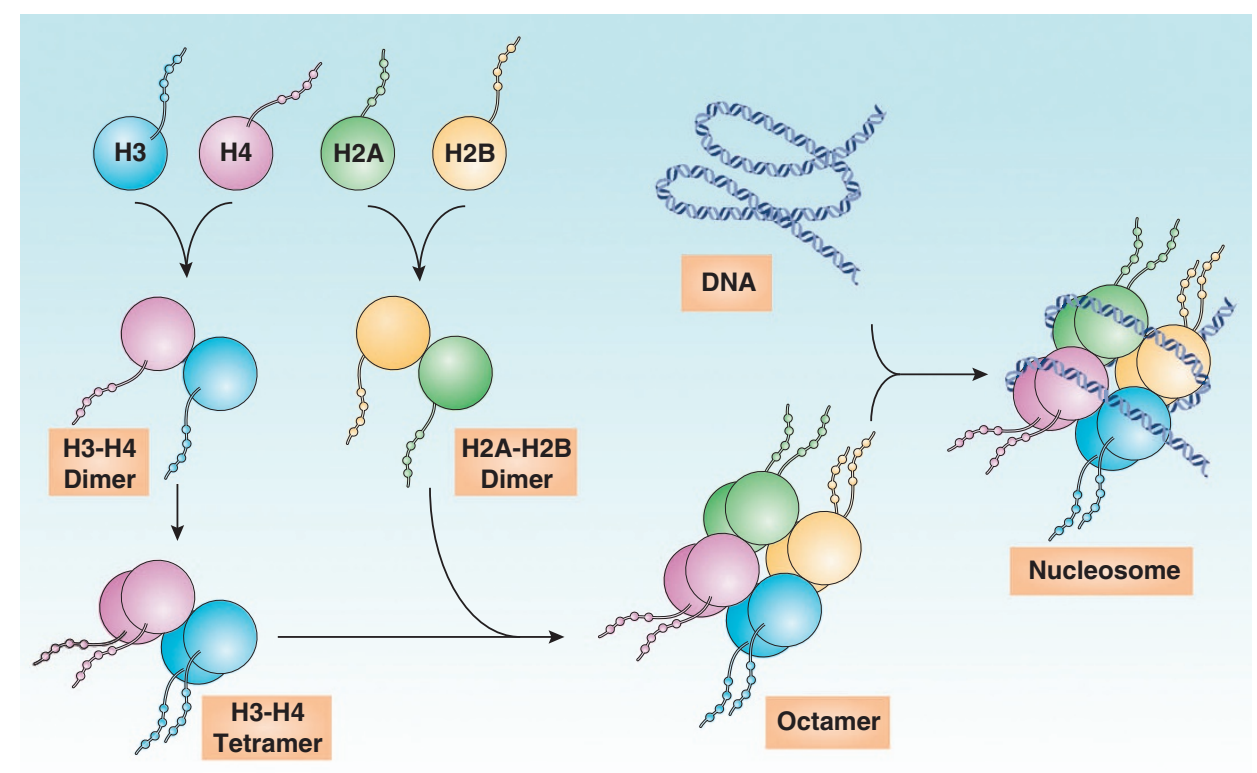

Figure 1 Histone structure and nucleosome assembly. A nucleosome contains an octamer of histone molecules. An octamer contains an $\mathrm{H} 3-\mathrm{H} 4$ tetramer and two H2A-H2B dimers. 


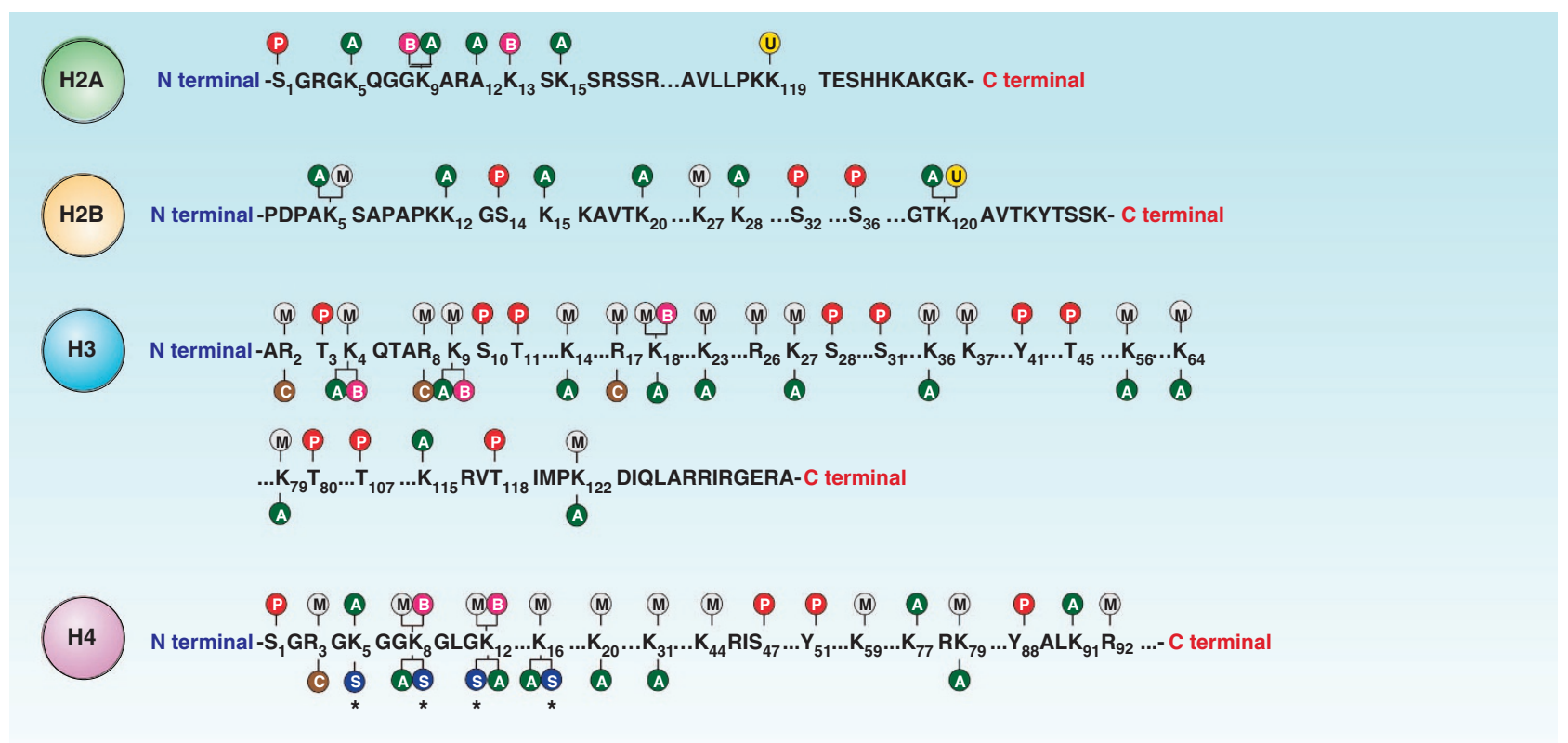

P Phosphorylation A Acetylation (4) Ubiquitination (M) Methylation C Cirullination S Sumoylation B Biotinylation

Figure 2 Histone modifications. The major modifications shown here include acetylation (A), methylation (M), phosphorylation (P), ubiquitination (U), citrullination (C), sumoylation (S), and biotinylation (B). Asterisk indicates that the modification is from S. cerevisiae

repressive heterochromatin to permissive euchromatin. This modification increases transcription factor binding to DNA and subsequent gene transcription and expression. Contrastingly, deacetylation of histones by histone deacetylases contributes to transcriptional silencing and gene suppression. However, methylation of histone lysine by histone methyltransferases has a dual role in regulating gene transcription, depending on the target residue. Moreover, histone methylation can cause DNA methylation and histone phosphorylation through regulating the binding between histone modification enzymes and chromatin. Increasing evidence indicates that histone aberrant modifications contribute to human diseases such as cancer, neurodevelopment disorders, neurodegenerative diseases, and pathogen infection. ${ }^{2,15}$

\section{Histone Release, NETs, and Cell Death}

In addition to nuclear function, histones have recently been demonstrated to function as endogenous danger signals or DAMPs when they translocate from the nucleus to the extranuclear space (Figure 3). H2A, H2B, H3, H4, and H1 are frequently detected at the cell surface or cytoplasm of immune cells, ${ }^{16-19}$ cerebellar neurons, ${ }^{20}$ Schwann cells, ${ }^{21}$ and microglia ${ }^{22}$ in response to stress. Levels of circulating histones as well as nucleosomes are increased in animals or patients with cancer, inflammation, and infection, suggesting an extracellular role of histones in human disease. ${ }^{5}$

Histone is released from activated immune cells (e.g., neutrophils ${ }^{23}$ and mast cells ${ }^{24}$ ) by extracellular traps. Extracellular traps are first observed in activated neutrophil in response to microbial infection. ${ }^{23}$ They are networks of extracellular fibers composed of neutrophil chromatin components (e.g., genomic DNA and core histones) and other antimicrobial factors, which capture and degrade invading microorganisms. Moreover, increased release of neutrophil extracellular traps (NETs) can lead to a unique form of immune cell death termed as 'NETosis'. In addition to NETosis-mediated histone release, apoptotic or necrotic cells can release histones that are usually associated with impaired phagocytosis $^{25}$ (Figure 4). Extracellular histones have been considered as potential mediators of lethal systemic inflammatory diseases including infection (e.g., sepsis ${ }^{6}$ and peritonitis ${ }^{26}$ ) and sterile inflammation (e.g., ischemia-reperfusion injury, ${ }^{27}$ pancreatitis, ${ }^{28}$ drug-induced tissue toxicity, ${ }^{29,30}$ and stroke ${ }^{31}$ ) (Figure 5). These findings suggest that histones are therapeutic targets for infectious and inflammatory disorders.

\section{Histone-Partner Molecule Complex}

Histones are positively charged, which allow them to bind negatively charged molecules. Histones directly bind DNA and form histone-DNA complexes to enhance the inflammatory response, thrombin generation, coagulation, and thrombogenesis in vivo and in vitro. ${ }^{30,32}$ In addition, extracellular histones are able to bind and induce aggregation of lowdensity lipoprotein in vitro, suggesting a possible role of histone in the regulation of the development of atherosclerosis. ${ }^{33}$ Polysialic acid (PSA) is a large and highly negatively charged glycan that has a crucial role in the regulation of the adult nervous system. $\mathrm{H} 1$ is present and colocalized with PSA at the cell surface of cerebellar neurons and Schwann cells. ${ }^{21}$ Membrane $\mathrm{H} 1$ stimulates neurogenesis, proliferation of Schwann cells, and migration of neural precursor cells in a 


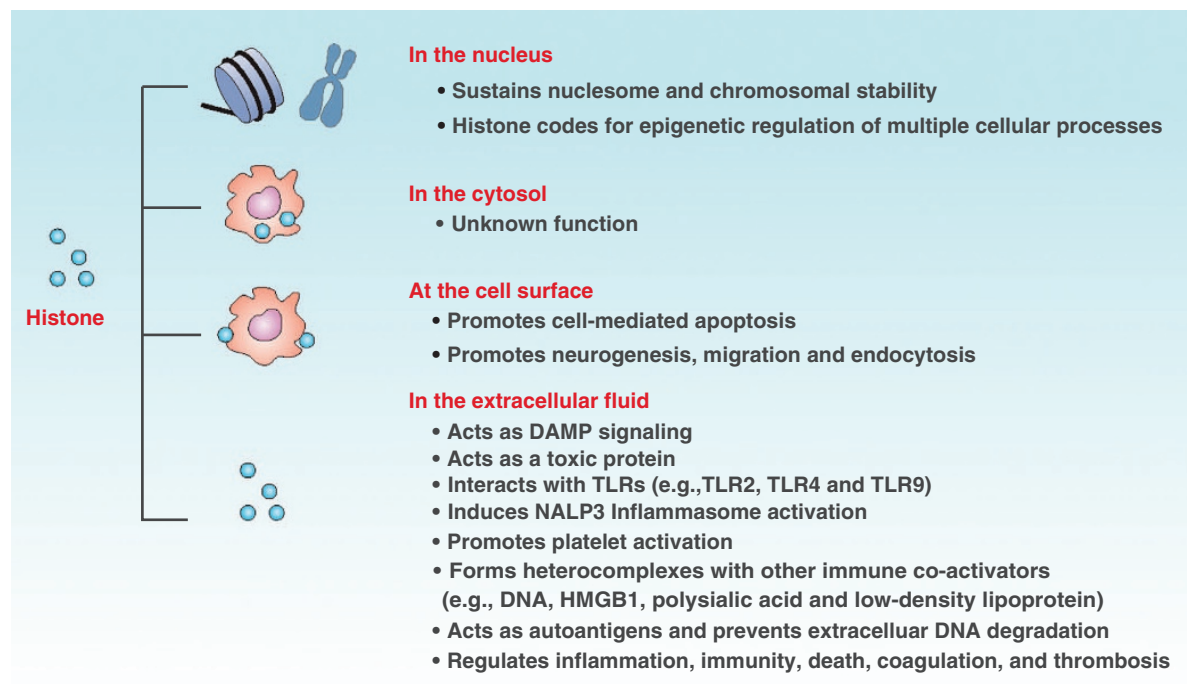

Figure 3 Histone location and function

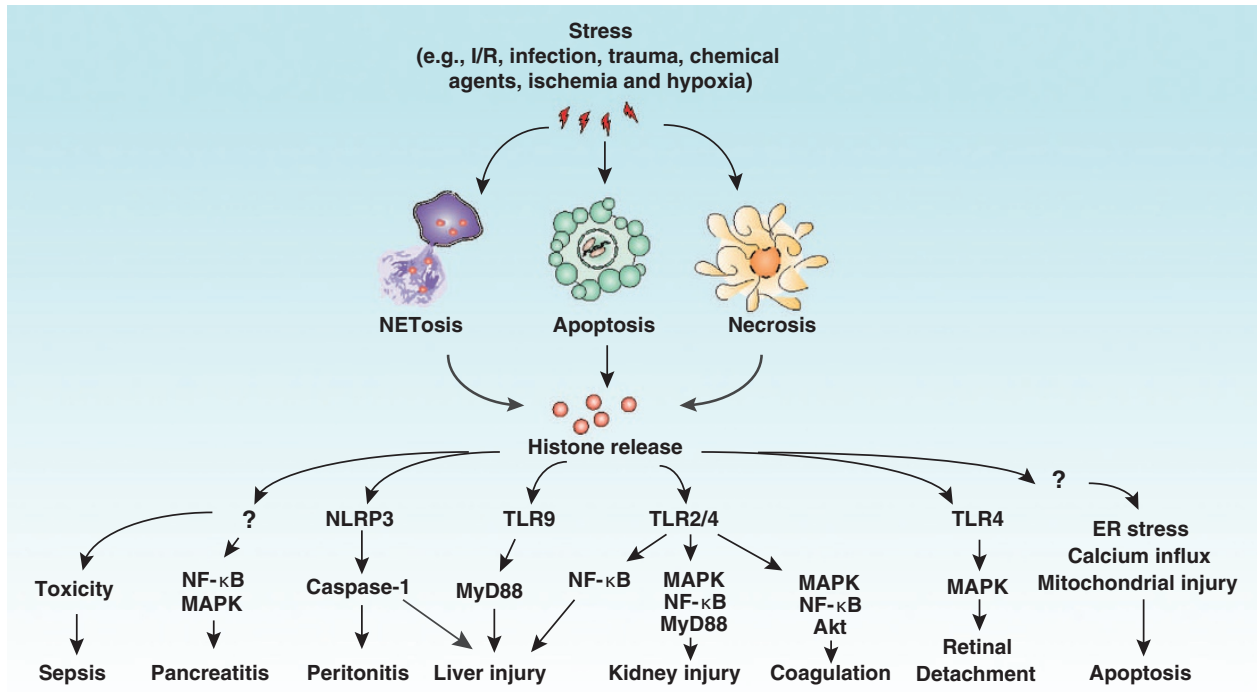

Figure 4 Release and activity of histones in response to stress

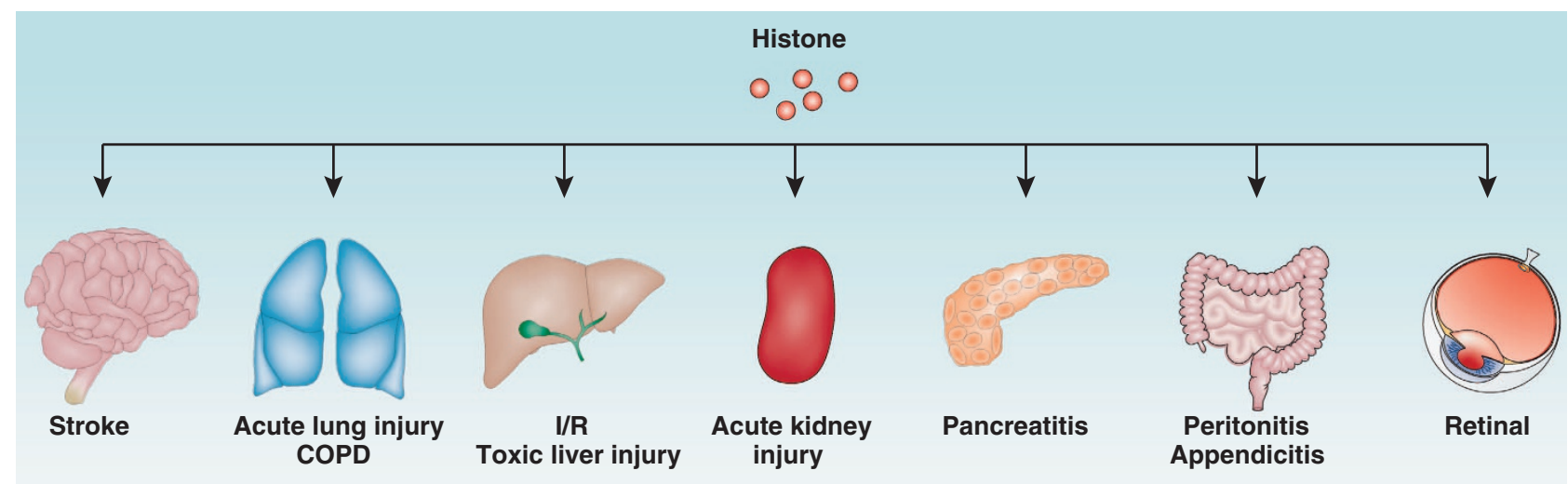

Figure 5 Histone-mediated tissue injury and disease 
PSA-dependent manner. ${ }^{21} \mathrm{H} 1$ also presents in the cell surface of macrophages, which mediates the binding and endocytosis of thyroglobulin. ${ }^{19}$ In addition, histones have the ability to bind heparin sulfate proteoglycans, ${ }^{34}$ lipopolysaccharide, ${ }^{20,35}$ amyloid precursor protein, ${ }^{36} \beta$-amyloid, ${ }^{37}$ and high mobility group box 1 (HMGB1). ${ }^{38}$ Of them, heparin and heparan sulfate act as negatively charged binding partners of histones. These findings suggest that histones work in a single or complex manner to regulate various cell processes.

\section{Pathologic Roles of Extracellular Histones}

Histones in apoptosis. Apoptotic cells are defined by two major morphological characteristics: chromatin condensation and DNA fragmentation. Thus, nuclear components are generally not released during apoptosis. However, increasing evidence indicates that cells undergoing apoptosis have the ability to release nuclear substances to the extracellular space. These nuclear substances include histone, HMGB1, DNA, and possibly other nuclear proteins. ${ }^{7}$ In response to apoptotic signals, core histones $(\mathrm{H} 2 \mathrm{~A}, \mathrm{H} 2 \mathrm{~B}, \mathrm{H} 3$, and $\mathrm{H} 4)$ as well as link histone $(\mathrm{H} 1)$ separate from genomic DNA, which results in histone cytoplasmic translocation and subsequent release into the extracellular space. ${ }^{39}$ Histone release is highly associated with DNA fragmentation during apoptosis. This process is primarily completed by caspase-activated DNase/DNA fragmentation factor. ${ }^{39}$ Histones are also involved in a self-sustaining cascade of apoptosis, which facilitates progression of chronic obstructive pulmonary disease (COPD). ${ }^{40}$ In particular, hyperacetylated $\mathrm{H} 3.3$ is resistant to proteasomal degradation, which causes H3.3 accumulation in the extracellular space. ${ }^{40}$ Extracellular H3.3 binds to lung structural cells and induces apoptosis through several mechanisms, including induction of calcium influx, enhancement of the endoplasmic reticulum unfolded protein response, and elevation of mitochondrial toxicity (Figure 4). In contrast, the use of $\mathrm{H} 3$-neutralizing antibodies can protect against H3.3-meditaed lung injury. ${ }^{40}$ These findings suggest that $\mathrm{H} 3.3$ released by apoptotic cells induces further apoptosis in lung cells, which establishes a vicious cycle. Interestingly, $\mathrm{H} 1$, but not the core histones, is released from damaged brain. ${ }^{41}$ Extracellular $\mathrm{H} 1$ is neurotoxic and induces significant neuronal death through activation of the mitochondrial apoptosis pathway. ${ }^{41}$ Exogenous histones also induce death in hair follicle progenitor cells. ${ }^{42}$ Thus, extracellular histone release and activity occurs in a cell- and tissue-specific manner. The exact intracellular mechanism underlying crosstalk between apoptosis-mediated histone release and subsequent extracellular histone-induced apoptosis is unknown and needs further investigation.

Histones in sepsis. Sepsis is a systemic inflammatory response syndrome primarily caused by bacterial infections. In 1958, Hirsch et al. ${ }^{43}$ observed that histone has a stronger ability to kill bacteria than many canonical antimicrobials. However, a recent study from $\mathrm{Xu}$ et $a l^{6}{ }^{6}$ indicates that extracellular histones are toxic in vitro and in vivo, which facilitates microvascular dysfunction during sepsis. Mice show increased levels of histones in serum after endotoxin administration. $\mathrm{H} 3$ and $\mathrm{H} 4$ are the major components responsible for this toxicity. ${ }^{6}$ In vitro, exogenous histones transient increase intracellular calcium concentration in endothelial cells; in vivo, histone administration causes neutrophil migration, endothelial injury and dysfunction, hemorrhage, and thrombosis, which finally result in animal death. ${ }^{6}$ In contrast, treatment with $\mathrm{H} 4$-neutralizing antibodies significantly decreases histone-mediated cell injury and protects against tissue injury and animal death in several sepsis models (e.g., endotoxemia, cecal ligation and puncture, and tumor necrosis factor- $\alpha$ (TNF- $\alpha$ ) treatment). ${ }^{6}$ Moreover, recombinant human activated protein C (APC) significantly reduces histone-mediated cytotoxicity by cleavage of histones in vitro and in vivo. ${ }^{6}$ However, there is no evidence to show that APC reduces the risk of death in patients with severe sepsis or septic shock. ${ }^{44}$ In addition, citrullinated $\mathrm{H} 3$ could be a potential serum biomarker for the early diagnosis of septic shock. ${ }^{45,46}$ Inhibition of production or activity of citrullinated $\mathrm{H} 3$ significantly improves survival in septic mice. ${ }^{45,46}$ Collectively, extracellular histones and their PTMs are critical mediators of sepsis and therefore may be potential therapeutic targets in infectious diseases.

Histones in trauma. Histones are released following trauma or severe cellular stress. A cohort study of 52 patients shows that serum histone levels are significantly elevated after severe non-thoracic blunt trauma. ${ }^{47}$ High serum histone levels positively correlate with severe complications, incidence, and dismal prognosis. In vitro, exogenous histones lead to production and secretion of a variety of cytokines (e.g., TNF- $\alpha$, IL-6, and IL-10), stimulate NET formation and myeloperoxidase release, and increase calcium influx in immune and endothelial cells, which partly mediates histone-induced cytotoxicity. ${ }^{47}$ In vivo, histone administration also accelerates cytokine release, endothelial damage, coagulation activation, and lung injury in animal trauma models. ${ }^{47}$ Histone-neutralizing antibody administration protects mice from histone-mediated lethality. ${ }^{47}$ These findings suggest that histone release has a key pathological role in trauma-associated injuries.

Histones in tissue injury. Ischemia/reperfusion (I/R) and drug-mediated tissue injury result in sterile inflammation, a process occurring in the absence of microorganisms. Serum histone levels are significantly elevated in animal models with liver, ${ }^{27,29,30}$ kidney, ${ }^{48}$ lung, ${ }^{49}$ and brain ${ }^{31}$ injury, suggesting an important role of histones in the regulation of sterile inflammation (Figure 5). Indeed, circulating histones are major mediators of animal death in several liver injury models including concanavalin A-triggered liver injury, acetaminophen-induced hepatotoxicity, liver I/R, and acute liver failure. Once released, histones selectively bind to Toll-like receptors (TLRs) including TLR2, ${ }^{30}$ TLR $4,{ }^{30}$ and $T_{R} 9^{27}$ to produce pro-inflammatory cytokines (e.g., TNF- $\alpha$ and IL-6), which in turn accelerates inflammatory responses and tissue injury (Figure 4). Histone and DNA have synergistic effects on activation of TLR signals. ${ }^{30}$ Treatment with histoneneutralizing antibody or knockout of TLR2, TLR4, and TLR9 in mice protects against histone-mediated liver injury. The myeloid differentiation factor 88 (MyD88) and NLRP3 inflammasome signaling pathway is required for 
histone-mediated liver I/R injury. ${ }^{27,50}$ Extracellular histones mediate not only liver, but also acute kidney injury or ischemic stroke through direct toxicity or pro-inflammatory effects. Similarly, TLR2 and TLR4-mediated signaling pathways (e.g., MyD88, NF-кB, and mitogen activated protein kinase (MAPK)) are responsible for extracellular histonemediated acute kidney injury. ${ }^{48}$ Histone infusion increases brain infarct size and exacerbates stroke outcome, whereas histone neutralization antibodies reduce infarct size. ${ }^{31}$ Serum $\mathrm{H} 3$ and H4 levels are remarkably increased in bronchoalveolar lavage fluid from acute lung injury (ALI) animal models or patients. ${ }^{49}$ Release of histones by NETs contributes to C5a receptor (C5aR and C5L2) pathway-mediated lung damage and inflammation because airway administration of histones causes $A L I$, whereas neutralizing antibody protects against ALI in animals. ${ }^{49}$ Collectively, extracellular histones function as DAMPs and mediate sterile inflammation and organ damage. Inhibition of histone release and activity could be a feasible therapeutic strategy for tissue injury.

Histones in peritonitis. Peritonitis is an inflammation of the peritoneum caused by bacterial or fungal infection. The inflammasome is a multiprotein complex that regulates the release of caspase (e.g., caspase-1 and caspase-11) dependent cytokine (e.g., IL-1 $\beta$ and IL-18) release, which contributes to multiple inflammatory diseases, including peritonitis. Histones released from necrotic cells have been identified as NLRP3 inflammasome agonists by activation of oxidative stress in vivo and in vitro (Figure 4). ${ }^{26}$ Administration of exogenous histones triggers neutrophil recruitment and IL-1 $\beta$ release in an NLRP3-caspase-1-dependent manner. In contrast, treatment with H4-neutralizing antibody and APC significantly limits histone-induced peritonitis. ${ }^{26}$

Histones in pancreatitis. Acute pancreatitis is characterized by sterile inflammation and acinar cell death, including necrosis and apoptosis. Our recent study indicated that extracellular histone-mediated HMGB1 release in activated immune cells is responsible for L-arginine-induced acute pancreatitis in HMGB1 pancreatic conditional knockout mice. ${ }^{28}$ Loss of HMGB1 in the pancreas increases histone ( $\mathrm{H} 3$ and $\mathrm{H} 4)$ release into the circulation after extensive nuclear injury and cell death. Circulating histones have the ability to recruit macrophages, resulting in macrophage activation and HMGB1 release. Importantly, H3- and HMGB1-neutralizing antibody remarkably protect against experimental acute pancreatitis in HMGB1 pancreatic conditional knockout mice. Similarly, knockout of HMGB1 in the liver also increases histone release in response to $\mathrm{I} / \mathrm{R}$ injury. ${ }^{51}$ These findings suggest that intracellular HMGB1 functions generally as an anti-inflammatory protein through sustaining nuclear homeostasis and histone release.

Histones in retinal detachment. Retinal detachment is a disorder of the eye in which the neural layer of the retina peels away from the retinal pigment epithelium, usually caused by a retinal break or tear. A recent study shows that intravitreal concentration of histones is higher in the eyes of patients with retinal detachment than in normal eyes. ${ }^{52}$ Extracellular histones are toxic and induce IL-8 production in vivo and in vitro through a TLR4/MAPK (ERK1/2 and p38)dependent pathway ${ }^{52}$ (Figure 4). Vitreous body hyaluronic acid decreases histone-mediated toxicity by inhibiting diffusion of histones. These findings indicate that histones released from dying retinas can act as DAMPs to induce pro-inflammatory cytokine release and mediate cell toxicity.

Histones in coagulation and thrombosis. Coagulation is the biological process by which blood forms clots. A precise regulation mechanism prevents aberrant coagulation that results in an increased risk of bleeding (hemorrhage) or obstructive clotting (thrombosis). Histone administration in mice increases microvascular thrombosis with loss of the vascular barrier, which contributes to multiple organ dysfunction and failure. ${ }^{6}$ As major component of NETs, histones including $\mathrm{H} 1, \mathrm{H} 2 \mathrm{~A}, \mathrm{H} 2 \mathrm{~B}, \mathrm{H} 3$, and $\mathrm{H} 4$ induce mouse platelet aggregation and subsequent platelet-dependent thrombin formation in vivo and in vitro. ${ }^{53}$ Of them, $\mathrm{H} 4$ has the strongest impact on platelet activity. ${ }^{53}$ Histones also induce a procoagulant phenotype in human platelets, which enhance thrombin generation and accelerate the blood clotting process. ${ }^{32}$ TLR2 and TLR4 are responsible for histonemediated platelet activation through activation of signaling pathways (e.g., ERK, Akt, p38, and NF- $\kappa \mathrm{B}$ ), induction of calcium influx, and fibrinogen recruitment (Figure 4). ${ }^{53}$ Histone-DNA complexes augment thrombin generation, whereas the administration of APC abolishes this process. ${ }^{32}$ Heparin and albumin neutralizes histone toxicity as well as histone-related platelet activation in vitro and in vivo. ${ }^{32,54-58}$ In addition, histone infusion increases plasma levels of von Willebrand factor in mice, which contributes to platelet activation and subsequent development of deep venous thrombosis. ${ }^{59}$ Besides platelets, histones impair the protein C-thrombomodulin system. Exogenous histones dose dependently increase plasma thrombin generation in the presence of thrombomodulin. ${ }^{56}$ Interestingly, recombinant thrombomodulin (rTM), which has been approved for the treatment of disseminated intravascular coagulation patients in Japan, directly binds histone and protects mice against lethal thrombosis in mice. ${ }^{60}$ The protective effects of rTM against histone toxicity are mediated through both APCdependent and -independent ways. The structural basis for rTM-histone binding remains unknown; more studies are needed to confirm the therapeutic values of rTM.

Histones in autoimmune and autoinflammatory disorders. Histone release from NETosis has been implicated in a number of autoimmune and autoinflammatory diseases such as rheumatoid arthritis, ${ }^{61}$ systemic lupus, ${ }^{62}$ small-vessel vasculitis, $^{63}$ and blood transfusion-related diseases. ${ }^{64}$ Besides acting as direct autoantigens in autoimmune disorders, extracellular histones can prevent DNA degradation through formation of histone-DNA complex, which enhances the autoimmune response. ${ }^{62}$ In addition, protein arginine deaminases (e.g, PDA4) mediate deimination and citrullination of histones, which in turn increase the immunogenicity of histones released from NETosis. ${ }^{65}$ Antibody binding to nucleosomes on glomerular cell surfaces has a role in lupus-related immune complex glomerulonephritis. ${ }^{66}$ 
Histones in central nervous system disease. Huntington's disease is an autosomal dominant neurodegenerative disorder caused by a polyglutamine repeat expansion, resulting in an expanded polyglutamine track in the huntingtin protein. Recent evidence indicates that histone modification-mediated transcriptional dysregulation is an important pathogenic mechanism in Huntington's disease. ${ }^{67}$ The pharmacologica manipulations of histone deacetylase activity have been beneficial in various experimental models of central nervous system disease such as Huntington's disease, epilepsy, and Alzheimer's disease. ${ }^{68}$ Neuronal death, inflammatory responses, and reactive gliosis are the markers of the major neurological diseases. More recent evidence indicates that extracellular histone $\mathrm{H} 1$ is a neurotoxic proinflammatory factor and causes reactive gliosis in central nervous system. ${ }^{41}$ These findings suggest that both histone modifications and extracellular histones contribute to central nervous system disease.

\section{Clinical Significance of Serum Histones and Nucleosomes}

Commercial enzyme-linked immunosorbent assay for nucleosomes is usually developed through using histone antibody. Serum levels of nucleosomes and histones are significantly elevated and possibly correlate with the severity or poor prognosis of several disorders such as acute bacterial infection, ${ }^{69}$ sepsis, ${ }^{70}$ autoimmune diseases (e.g., systemic lupus erythematosus), ${ }^{71,72}$ cerebral stroke, ${ }^{73}$ trauma, ${ }^{74}$ and cancer. $^{69,75-77}$ Either increased apoptosis or impaired phagocytosis results in increased exposure of apoptotic nucleosomes to the immune system in patients. These nucleosomes lead to breaking of immune tolerance and development of autoimmunity through the activation of $T$ cells and $B$ cells and subsequent production of large amounts of anti-nucleosome, anti-histone, and anti-DNA autoantibodies. The presence of anti-nucleosome antibody deposits closely correlates with lupus nephritis. ${ }^{72}$

High concentrations of serum nucleosomes are detected in patients with cerebral stroke, especially in patients with large infarction volumes. ${ }^{78}$ Serum nucleosome levels rise quickly after post-ischemia, peak at days $3-5$, and then fall slowly. Moreover, circulating nucleosome levels in combination with clinical Barthel scores provide independent and valuable prognostic information in stroke patients with initially functional deficits. ${ }^{73}$

In a prognostic study of 132 critically injured trauma patients, circulating histones increased quickly after trauma. ${ }^{74}$ Increased serum histones were positively and negatively related to injury severity score and Glasgow Coma Score, respectively. High serum histones contribute to acute lung injury, multiorgan failure, and even mortality in trauma patients because histones can cause coagulopathy, fibrinolysis, and activation of systemic anticoagulation. ${ }^{47}$ Trauma also leads to the increase in serum histone-complexed DNA fragment (hcDNA) levels in patients, which positively correlate with biomarkers of coagulopathy, inflammation, and endothelial damage. ${ }^{74}$

In patients with different types of tumors, especially in advanced cancer, serum nucleosome levels are significantly higher compared with those in healthy populations. ${ }^{69,75-77,79}$
Serum nucleosome levels are also elevated in benign tumors as well as precancerous lesions, which may increase the difficulties in differential diagnosis of cancer and inflammationassociated disease. ${ }^{80}$ The clinical value of serum nucleosome/histone tests for diagnosis and prognosis may change depending on tumor type and analysis method. ${ }^{81}$ For example, serum nucleosomes correlate with tumor stage and distant metastase only in patients with gastrointestinal cancer, but not those with other tumor types. ${ }^{69,82}$ Circulating nucleosomes have had a significant prognostic impact on cancer patients in univariate analyses, but not in multivariate analyses. ${ }^{81,82}$ In addition, monitoring of extracellular nucleosome levels contributes a lot to the assessment of the response to cytotoxic therapy including chemotherapy and radiotherapy in patients with colorectal, ${ }^{79}$ pancreatic, ${ }^{83}$ and lung cancer ${ }^{77}$ as well as hematologic malignancies. ${ }^{84}$ Taken together, serum histones and nucleosomes can indicate a variety of health or disease characteristics and may be useful biomarkers for diseases, especially cancer.

Conclusions and perspectives. Histones, as chromatin structure proteins, have recently been discovered to function as DAMPs involved in multiple cellular processes. In the past 5 years, a significant progress has been made toward understanding the release and activity of histones in response to stress. Activated immune cells and injured cells release histones into the extracellular space, where they bind to receptors (e.g., TLRs) and trigger activation of multiple signaling pathways (e.g., MAPK, NF- $\kappa \mathrm{B}, \mathrm{AKT}$, and inflammasome) in a single or combined manner. Extracellular histones may be useful biomarkers that will improve the diagnosis, prognosis, and management of human diseases. Anti-histone-based therapeutic strategies may also be useful in treating several diseases. However, understanding the structure, modification, and function of histones inside and outside cells remains challenging.

\section{Conflict of Interest}

The authors declare no conflict of interest.

Acknowledgements. We apologize to the researchers who were not referenced due to space limitations. We thank Christine Heiner (Department of Surgery, University of Pittsburgh) for her critical reading of the manuscript. This work was supported by the National Institutes of Health (R01CA160417 to DT) and a 2013 Pancreatic Cancer Action Network-AACR Career Development Award (Grant Number 13-20-25-TANG) and the National Natural Sciences Foundation of China (grant 81272253 to X-G Fan). Work done in support of findings reviewed in this manuscript was aided by the Core Support of the UPCI(P30CA047904).

\section{Author Contributions}

$\mathrm{RC}, \mathrm{RK}, \mathrm{XF}$, and DT contributed to the writing of this review.

1. Campos El, Reinberg D. Histones: annotating chromatin. Annu Rev Genet 2009; 43: 559-599.

2. Bhaumik SR, Smith E, Shilatifard A. Covalent modifications of histones during development and disease pathogenesis. Nat Struct Mol Biol 2007; 14: 1008-1016.

3. Zentner GE, Henikoff S. Regulation of nucleosome dynamics by histone modifications. Nat Struct Mol Biol 2013; 20: 259-266.

4. Strahl BD, Allis CD. The language of covalent histone modifications. Nature 2000; 403: 41-45.

5. Allam R, Kumar SV, Darisipudi MN, Anders HJ. Extracellular histones in tissue injury and inflammation. J Mol Med (Berl) 2014; 92: 465-472. 
6. Xu J, Zhang X, Pelayo R, Monestier M, Ammollo CT, Semeraro F et al. Extracellular histones are major mediators of death in sepsis. Nat Med 2009; 15: 1318-1321.

7. Hou W, Zhang Q, Yan Z, Chen R, Zeh lii HJ, Kang R et al. Strange attractors: DAMPs and autophagy link tumor cell death and immunity. Cell Death Dis 2013; 4: e966.

8. Tang D, Kang R, Coyne CB, Zeh HJ, Lotze MT. PAMPs and DAMPs: signal Os that spur autophagy and immunity. Immunol Rev 2012; 249: 158-175.

9. Zhang Q, Kang R, Zeh 3rd HJ, Lotze MT, Tang D. DAMPs and autophagy: cellular adaptation to injury and unscheduled cell death. Autophagy 2013; 9: 451-458.

10. Andrews AJ, Luger K. Nucleosome structure(s) and stability: variations on a theme. Annu Rev Biophys 2011; 40: 99-117.

11. Jiang $\mathrm{C}$, Pugh BF. Nucleosome positioning and gene regulation: advances through genomics. Nat Rev Genet 2009; 10: 161-172.

12. Latham JA, Dent SY. Cross-regulation of histone modifications. Nat Struct Mol Biol 2007; 14: 1017-1024.

13. Bird A. Perceptions of epigenetics. Nature 2007; 447: 396-398.

14. Bedford MT, Clarke SG. Protein arginine methylation in mammals: who, what, and why. $\mathrm{Mol}$ Cell 2009; 33: 1-13.

15. Portela A, Esteller M. Epigenetic modifications and human disease. Nat Biotechnol 2010; 28: 1057-1068.

16. Watson K, Edwards RJ, Shaunak S, Parmelee DC, Sarraf C, Gooderham NJ et al. Extra-nuclear location of histones in activated human peripheral blood lymphocytes and cultured T-cells. Biochem Pharmacol 1995; 50: 299-309.

17. Gabler C, Blank N, Hieronymus T, Schiller M, Berden JH, Kalden JR et al. Extranuclear detection of histones and nucleosomes in activated human lymphoblasts as an early event in apoptosis. Ann Rheum Dis 2004; 63: 1135-1144.

18. Hefeneider SH, Cornell KA, Brown LE, Bakke AC, McCoy SL, Bennett RM. Nucleosomes and DNA bind to specific cell-surface molecules on murine cells and induce cytokine production. Clin Immunol Immunopathol 1992; 63: 245-251.

19. Brix K, Summa W, Lottspeich F, Herzog V. Extracellularly occurring histone H1 mediates the binding of thyroglobulin to the cell surface of mouse macrophages. J Clin Invest 1998; 102: 283-293

20. Bolton SJ, Perry VH. Histone H1; a neuronal protein that binds bacterial lipopolysaccharide. J Neurocytol 1997; 26: 823-831.

21. Mishra B, von der Ohe M, Schulze C, Bian S, Makhina T, Loers G et al. Functional role of the interaction between polysialic acid and extracellular histone H1. J Neurosci 2010; 30: 12400-12413.

22. Klein B, Lutz-Meindl U, Kerschbaum HH. From the nucleus to the plasma membrane: translocation of the nuclear proteins histone $\mathrm{H} 3$ and lamin B1 in apoptotic microglia. Apoptosis 2014; 19: 759-775.

23. Brinkmann V, Reichard U, Goosmann C, Fauler B, Uhlemann Y, Weiss DS et al. Neutrophil extracellular traps kill bacteria. Science 2004; 303: 1532-1535.

24. von Kockritz-Blickwede M, Goldmann O, Thulin P, Heinemann K, Norrby-Teglund A, Rohde $\mathrm{M}$ et al. Phagocytosis-independent antimicrobial activity of mast cells by means of extracellular trap formation. Blood 2008; 111: 3070-3080.

25. Jahr S, Hentze H, Englisch S, Hardt D, Fackelmayer FO, Hesch RD et al. DNA fragments in the blood plasma of cancer patients: quantitations and evidence for their origin from apoptotic and necrotic cells. Cancer Res 2001; 61: 1659-1665.

26. Allam R, Darisipudi MN, Tschopp J, Anders HJ. Histones trigger sterile inflammation by activating the NLRP3 inflammasome. Eur J Immunol 2013; 43: 3336-3342.

27. Huang H, Evankovich J, Yan W, Nace G, Zhang L, Ross M et al. Endogenous histones function as alarmins in sterile inflammatory liver injury through Toll-like receptor 9 in mice. Hepatology 2011; 54: 999-1008.

28. Kang R, Zhang Q, Hou W, Yan Z, Chen R, Bonaroti J et al. Intracellular Hmgb1 Inhibits Inflammatory Nucleosome Release and Limits Acute Pancreatitis in Mice. Gastroenterology 2014; 146: 1097-1107.

29. Wen Z, Liu Y, Li F, Ren F, Chen D, Li X et al. Circulating histones exacerbate inflammation in mice with acute liver failure. J Cell Biochem 2013; 114: 2384-2391.

30. Xu J, Zhang X, Monestier M, Esmon NL, Esmon CT. Extracellular histones are mediators of death through TLR2 and TLR4 in mouse fatal liver injury. J Immunol 2011; 187: 2626-2631.

31. De Meyer SF, Suidan GL, Fuchs TA, Monestier M, Wagner DD. Extracellular chromatin is an important mediator of ischemic stroke in mice. Arterioscler Thromb Vasc Biol 2012; 32: 1884-1891.

32. Semeraro F, Ammollo CT, Morrissey JH, Dale GL, Friese $\mathrm{P}$, Esmon NL et al. Extracellular histones promote thrombin generation through platelet-dependent mechanisms: involvement of platelet TLR2 and TLR4. Blood 2011; 118: 1952-1961.

33. Pemberton AD, Brown JK. In vitro interactions of extracellular histones with LDL suggest a potential pro-atherogenic role. PLOS One 2010; 5: e9884.

34. Henriquez JP, Casar JC, Fuentealba L, Carey DJ, Brandan E. Extracellular matrix histone $\mathrm{H} 1$ binds to perlecan, is present in regenerating skeletal muscle and stimulates myoblast proliferation. J Cell Sci 2002; 115(Pt 10): 2041-2051.

35. Hampton RY, Golenbock DT, Raetz CR. Lipid A binding sites in membranes of macrophage tumor cells. J Biol Chem 1988; 263: 14802-14807.

36. Duce JA, Smith DP, Blake RE, Crouch PJ, Li QX, Masters CL et al. Linker histone H1 binds to disease associated amyloid-like fibrils. J Mol Biol 2006; 361: 493-505.

37. Currie JR, Chen-Hwang MC, Denman R, Smedman M, Potempska A, Ramakrishna N et al. Reduction of histone cytotoxicity by the Alzheimer beta-amyloid peptide precursor. Biochim Biophys Acta 1997; 1355: 248-258.
38. Urbonaviciute V, Furnrohr BG, Meister S, Munoz L, Heyder P, De Marchis F et al. Induction of inflammatory and immune responses by HMGB1-nucleosome complexes: implications for the pathogenesis of SLE. J Exp Med 2008; 205: 3007-3018.

39. Wu D, Ingram A, Lahti JH, Mazza B, Grenet J, Kapoor A et al. Apoptotic release of histones from nucleosomes. J Biol Chem 2002; 277: 12001-12008.

40. Barrero CA, Perez-Leal O, Aksoy M, Moncada C, Ji R, Lopez Y et al. Histone 3.3 participates in a self-sustaining cascade of apoptosis that contributes to the progression of chronic obstructive pulmonary disease. Am J Respir Crit Care Med 2013; 188: 673-683.

41. Gilthorpe JD, Oozeer F, Nash J, Calvo M, Bennett DL, Lumsden A et al. Extracellular histone $\mathrm{H} 1$ is neurotoxic and drives a pro-inflammatory response in microglia. F1000Res 2013; 2: 148

42. Shin SH, Joo HW, Kim MK, Kim JC, Sung YK. Extracellular histones inhibit hair shaft elongation in cultured human hair follicles and promote regression of hair follicles in mice. Exp Dermatol 2012; 21: 956-958.

43. Hirsch JG. Bactericidal action of histone. J Exp Med 1958; 108: 925-944.

44. Marti-Carvajal AJ, Sola I, Lathyris D, Cardona AF. Human recombinant activated protein C for severe sepsis. Cochrane Database Syst Rev 2012; 3: CD004388.

45. Li Y, Liu Z, Liu B, Zhao T, Chong W, Wang Y et al. Citrullinated histone H3: A novel target for the treatment of sepsis. Surgery 2014; 156: 229-234.

46. Li Y, Liu B, Fukudome EY, Lu J, Chong W, Jin G et al. Identification of citrullinated histone $\mathrm{H} 3$ as a potential serum protein biomarker in a lethal model of lipopolysaccharide-induced shock. Surgery 2011; 150: 442-451.

47. Abrams ST, Zhang N, Manson J, Liu T, Dart C, Baluwa F et al. Circulating histones are mediators of trauma-associated lung injury. Am J Respir Crit Care Med 2013; 187: 160-169.

48. Allam R, Scherbaum CR, Darisipudi MN, Mulay SR, Hagele H, Lichtnekert J et al. Histones from dying renal cells aggravate kidney injury via TLR2 and TLR4. J Am Soc Nephrol 2012; 23: $1375-1388$.

49. Bosmann M, Grailer JJ, Ruemmler R, Russkamp NF, Zetoune FS, Sarma JV et al. Extracellular histones are essential effectors of C5aR-and C5L2-mediated tissue damage and inflammation in acute lung injury. Faseb J 2013; 27: 5010-5021.

50. Huang H, Chen HW, Evankovich J, Yan W, Rosborough BR, Nace GW et al. Histones activate the NLRP3 inflammasome in Kupffer cells during sterile inflammatory liver injury J Immunol 2013; 191: 2665-2679.

51. Huang H, Nace GW, McDonald KA, Tai S, Klune JR, Rosborough BR et al. Hepatocyte specific HMGB1 deletion worsens the injury in liver ischemia/reperfusion: a role for intracellular HMGB1 in cellular protection. Hepatology 2014; 59: 1984-1997.

52. Kawano H, Ito T, Yamada S, Hashiguchi T, Maruyama I, Hisatomi T et al. Toxic effects of extracellular histones and their neutralization by vitreous in retinal detachment. Lab Invest 2014; 94: 569-585.

53. Carestia A, Rivadeneyra L, Romaniuk MA, Fondevila C, Negrotto S, Schattner M. Functional responses and molecular mechanisms involved in histone-mediated platelet activation. Thromb Haemost 2013; 110: 1035-1045.

54. Fuchs TA, Bhandari AA, Wagner DD. Histones induce rapid and profound thrombocytopenia in mice. Blood 2011; 118: 3708-3714.

55. Wildhagen KC, Garcia de Frutos P, Reutelingsperger CP, Schrijver R, Areste C, Ortega-Gomez A et al. Nonanticoagulant heparin prevents histone-mediated cytotoxicity in vitro and improves survival in sepsis. Blood 2014; 123: 1098-1101.

56. Ammollo CT, Semeraro F, Xu J, Esmon NL, Esmon CT. Extracellular histones increase plasma thrombin generation by impairing thrombomodulin-dependent protein $\mathrm{C}$ activation. J Thromb Haemost 2011; 9: 1795-1803.

57. Fuchs TA, Brill A, Duerschmied D, Schatzberg D, Monestier M, Myers Jr. DD et al. Extracellular DNA traps promote thrombosis. Proc Natl Acad Sci USA 2010; 107: 15880-15885.

58. Lam FW, Cruz MA, Leung HC, Parikh KS, Smith CW, Rumbaut RE. Histone induced platelet aggregation is inhibited by normal albumin. Thromb Res 2013; 132: 69-76.

59. Brill A, Fuchs TA, Savchenko AS, Thomas GM, Martinod K, De Meyer SF et al. Neutrophil extracellular traps promote deep vein thrombosis in mice. J Thromb Haemost 2012; 10: 136-144.

60. Nakahara M, Ito T, Kawahara K, Yamamoto M, Nagasato T, Shrestha B et al. Recombinant thrombomodulin protects mice against histone-induced lethal thromboembolism. PLoS One 2013; 8: e75961.

61. Monach PA, Hueber W, Kessler B, Tomooka BH, BenBarak M, Simmons BP et al. A broad screen for targets of immune complexes decorating arthritic joints highlights deposition of nucleosomes in rheumatoid arthritis. Proc Natl Acad Sci USA 2009; 106: 15867-15872.

62. Hakkim A, Furnrohr BG, Amann K, Laube B, Abed UA, Brinkmann V et al. Impairment of neutrophil extracellular trap degradation is associated with lupus nephritis. Proc Natl Acad Sci USA 2010; 107: 9813-9818.

63. Kessenbrock K, Krumbholz M, Schonermarck U, Back W, Gross WL, Werb Z et al. Netting neutrophils in autoimmune small-vessel vasculitis. Nat Med 2009; 15: 623-625.

64. Fuchs TA, Alvarez JJ, Martinod K, Bhandari AA, Kaufman RM, Wagner DD. Neutrophils release extracellular DNA traps during storage of red blood cell units. Transfusion 2013; 53 : 3210-3216.

65. Dwivedi N, Radic M. Citrullination of autoantigens implicates NETosis in the induction of autoimmunity. Ann Rheum Dis 2014; 73: 483-491.

66. Mortensen ES, Rekvig OP. Nephritogenic potential of anti-DNA antibodies against necrotic nucleosomes. J Am Soc Nephrol 2009; 20: 696-704.

67. Sadri-Vakili G, Cha JH. Mechanisms of disease: Histone modifications in Huntington's disease. Nat Clin Pract Neurol 2006; 2: 330-338. 
68. Kazantsev AG, Thompson LM. Therapeutic application of histone deacetylase inhibitors for central nervous system disorders. Nat Rev Drug Discov 2008; 7: 854-868.

69. Holdenrieder S, Stieber P, Bodenmuller H, Busch M, Fertig G, Furst $\mathrm{H}$ et al. Nucleosomes in serum of patients with benign and malignant diseases. Int $J$ Cancer 2001; 95: 114-120.

70. Zeerleder S, Zwart B, Wuillemin WA, Aarden LA, Groeneveld AB, Caliezi C et al. Elevated nucleosome levels in systemic inflammation and sepsis. Crit Care Med 2003; 31 1947-1951.

71. Holdenrieder S, Eichhorn P, Beuers U, Samtleben W, Schoenermarck U, Zachoval R et al. Nucleosomal DNA fragments in autoimmune diseases. Ann NY Acad Sci 2006; 1075 318-327.

72. Schmiedeke TM, Stockl FW, Weber R, Sugisaki Y, Batsford SR, Vogt A. Histones have high affinity for the glomerular basement membrane. Relevance for immune complex formation in lupus nephritis. J Exp Med 1989; 169: 1879-1894.

73. Geiger S, Holdenrieder S, Stieber P, Hamann GF, Bruening R, Ma J et al. Nucleosomes as a new prognostic marker in early cerebral stroke. J Neurol 2007; 254: 617-623.

74. Johansson PI, Windelov NA, Rasmussen LS, Sorensen AM, Ostrowski SR. Blood levels of histone-complexed DNA fragments are associated with coagulopathy, inflammation and endothelial damage early after trauma. J Emerg Trauma Shock 2013; 6: 171-175.

75. Holdenrieder S, Stieber P, Forg T, Kuhl M, Schulz L, Busch M et al. Apoptosis in serum of patients with solid tumours. Anticancer Res 1999; 19: 2721-2724.

76. Kuroi K, Tanaka $\mathrm{C}$, Toi M. Plasma nucleosome levels in node-negative breast cancer patients. Breast Cancer 1999; 6: 361-364.

77. Holdenrieder S, Stieber P, von Pawel J, Raith H, Nagel D, Feldmann K et al. Circulating nucleosomes predict the response to chemotherapy in patients with advanced non-small cell lung cancer. Clin Cancer Res 2004; $10(18$ Pt 1): 5981-5987.

78. Geiger S, Holdenrieder S, Stieber P, Hamann GF, Bruening R, Ma J et al. Nucleosomes in serum of patients with early cerebral stroke. Cerebrovasc Dis 2006; 21: 32-37.
79. Fahmueller YN, Nagel D, Hoffmann RT, Tatsch K, Jakobs T, Stieber P et al. Predictive and prognostic value of circulating nucleosomes and serum biomarkers in patients with metastasized colorectal cancer undergoing Selective Internal Radiation Therapy. BMC Cancer 2012; 12: 5

80. Holdenrieder S, Nagel D, Schalhorn A, Heinemann V, Wilkowski R, von Pawel J et al. Clinical relevance of circulating nucleosomes in cancer. Ann NY Acad Sci 2008; 1137: 180-189.

81. Holdenrieder S, Mueller S, Stieber P. Stability of nucleosomal DNA fragments in serum. Clin Chem 2005; 51: 1026-1029.

82. Holdenrieder S, Stieber P, Bodenmuller H, Busch M, Von Pawel J, Schalhorn A et al. Circulating nucleosomes in serum. Ann NY Acad Sci 2001; 945: 93-102.

83. Kremer A, Wilkowski R, Holdenrieder S, Nagel D, Stieber P, Seidel D. Nucleosomes in pancreatic cancer patients during radiochemotherapy. Tumour Biol 2005; 26: 44-49.

84. Mueller S, Holdenrieder S, Stieber P, Haferlach T, Schalhorn A, Braess J et al. Early prediction of therapy response in patients with acute myeloid leukemia by nucleosomal DNA fragments. BMC Cancer 2006; 6: 143

cc)(-) $\Theta$ Cell Death and Disease is an open-access journal published by Nature Publishing Group. This work is licensed under a Creative Commons Attribution-NonCommercialNoDerivs 3.0 Unported License. The images or other third party material in this article are included in the article's Creative Commons license, unless indicated otherwise in the credit line; if the material is not included under the Creative Commons license, users will need to obtain permission from the license holder to reproduce the material. To view a copy of this license, visit http://creativecommons.org/licenses/ by-nc-nd/3.0/ 